The different physical conditions there are primarily responsible for the change in the character of the fauna as compared with that at Low Isles.

This report is most beautifully illustrated by a series of large-scale maps in picture form, showing in detail the distribution of corals and other organisms on small selected areas of the traverses or on portions of the Outer Barrier Reef. These maps show evidence of lavish care and attention both in the preliminary drawings and in the measurements necessary to produce them, as well as in the skilful draughtsmanship that has produced the finished plates. They should be of great value to all students of coral reef ecology.

\title{
Diesel Fuels and Engineering
}

$\mathrm{A}^{\mathrm{T}}$

$\mathrm{T}$ the first overseas meeting of the Institution of Petroleum Technologists held in Holland on May 8-11, a series of papers was read on diesel fuels and diesel engineering.

Among papers presented for discussion was one by Ir. W. Hupkes on "Diesel-Electric Traction on the Netherlands Railways". Of particular interest in this paper is a clear exposition of facts leading to selection of diesel-electric trains for the frequent and regular conveyance of passengers in the Netherlands. The triple-articulated diesel-electric engine chosen was designed specifically to meet circumstances of accommodation, coupling, speed, rapid acceleration and open-air storage when not in service. Full details are given of the car arrangement ultimately decided upon, motive power, performance, braking, automatic coupling, heating and ventilation.

Ir. G. J. Lugt in his paper on the "Design of Fuel Injectors for Diesel Engines" described the two methods of fuel injection, mechanical and pneumatic, and indicated the function of the injector as being the distribution of the fuel over the air in the compression space of the cylinder. $\mathrm{He}$ then devoted himself to closed mechanical injectors as being almost exclusively used by diesel engineers. $\mathrm{He}$ concluded with the remark that there is now little need for individual design of injectors for diesel engines as they have become to all intents and pur. poses a standard fitting.

Mr. C. H. Barton in his paper on "Diesel Fuel Specifications" pointed out the necessity for such specifications in the classification of fuels into grades and in the indication of desirable properties in par. ticular grades. He described tests commonly adopted in fuel specifications and indicated their significance.

A joint paper by Ir. G. D. Boerlage, Ir. J. J. Broeze, L. J. Le Mesurier and R. Stansfield, on the "Correlation of Tests on the Ignition Quality of Diesel Fuels, carried out at Delft and Sunbury", was the outcome of differences found in the two laboratories regarding the rating in terms of cetene numbers of some commercial fuels. A great deal of work was involved before agreement was reached, and the results of this collaboration are of major importance as providing a feasible technique for the accurate determination of ignition quality of diesel fuels.

\section{Training of the Engineer in the U.S.A.}

\begin{abstract}
A PAPER on the training of the young engineer by R. E. Hellmund, of the Westinghouse Company, just published by the American Institute of Electrical Engineers, takes into account the changing conditions of the industry recovering from the great depression. It was discussed at the summer convention of the American Institute of Electrical Engineers at Pasadena on June 26, 1936.

The disorganization of industry brought about in the United States and elsewhere by bad times has resulted in many radical suggestions being made in connexion with engineering education, and $\mathrm{Mr}$. Hellmund has noted a tendency to discard good methods with bad. Even if it were desirable for the good of humanity to retard the introduction of labour-saving devices with the object of avoiding unemployment, it would not be advisable. Every engineer employed in any competitive industrial enterprise must, if the business is to survive, reduce costs by every means in his power. Even the greatest advocates of Government control have never suggested the elimination of competition in industry. He states that the only way the engineer can help to diminish unemployment is to create new products
\end{abstract}

for which there will be a demand. This will enable costs to be reduced, and at the same time the population will benefit by the improvement. He suggests, therefore, that economics be given a more prominent place in engineering education. Psychology is another subject of study that will assist the engineer in carrying on his work effectively under modern conditions. The question arises, in what way should the syllabuses of the colleges be best altered so as to accomplish this.

Mr. Hellmund has noticed that young engineers in industrial organizations frequently become so ab. sorbed in the solution of an interesting problem that they neglect to study its economic and commercial aspects. During the depression, it was more than ever necessary to focus attention on this side of the question. In many college curricula, courses in economics are included, but they are given by the department of economics, and much of the work covered at present is far removed from the practical applications encountered by the engineer in his everyday work. He concludes that the engineering schools should offer special abbreviated courses which show how the basic laws can be applied in practice. 
Psychology is another subject that in several ways can assist the engineer in carrying on his work effectively. In industrial organizations, work cannot be done efficiently without a thorough knowledge of human nature. The depression has emphasized the importance of this. Although the study of psychology will not correct all personal shortcomings, yet it seems the only practical way by which the colleges can bring about improvement. A few specific lectures on this subject would be helpful in a school of engineering, but, at least at first, they should not be made compulsory.

Graduate courses at college prior to entering industry are, in Mr. Hellmund's opinion, only of limited value. It is dangerous for an engineering student to stay too long in a college atmosphere. The profession is one which requires courage and initiative, qualities which are rarely developed in college life by the type of students who take postgraduate courses. It is true that there are a few kinds of highly technical research work which might advantageously be done at a postgraduate course at the university. If the postgraduate work is undertaken because the graduate is unable to find immediate employment in industry, it is advisable not to take courses in the specific subjects of the branch of engineering contemplated but in affiliated subjects. For example, an engineer wishing to enter research work on electrical subjects would do well to take additional mathematies, physics and physical chemistry. One intending to take up practical design would find additional work relating to the materials used in his type of engineering, such as chemistry and metallurgy, very useful. The opinion is expressed that it is generally better for the young engineer to enter industry as soon as possible after completing his undergraduate course.

During the depression, the business of many industries deereased by $20-60$ per cent of previous levels. The heavy industries were as a rule the most severely affected. During the lowest level, it was difficult for engineering graduates to find employment. Now industry is increasing and the prospects are good. As a rule, employers can engage their old employees with specific experience and ability, but some of these have taken up activities outside the engineering industry and so there is a demand for young engineers. In some cases the latter have a great advantage over the older men, as they know the latest theories and methods and have not forgotten how to handle the technical details in calcu. lations, laboratory and similar work.

Mr. Hellmund has noticed that about seventy per cent of all engineering graduates express a desire to go into power transmission work, the design of large machinery, railway electrification and similar work. As they all cannot get employment in this direction, it is necessary to persuade some of them to take up other activities. 'The author can recall no instance where the men who took his advice afterwards regretted their action, as they soon found that there are very interesting and important problems in almost every branch of engineering. The young engineer need not fear to enter work not entirely in accord with his wishes. He should prepare himself to handle effectively the work assigned to him.

\section{Chemistry of Fibres}

THREE papers read at the annual conference of the Textile Institute held in London on June 3-6 dealt with various aspects of the chemistry of fibres.

One of these was a comprehensive summary by G. F. Davidson of current theories of the molecular structure of cellulose. After an outline of the chemical and physical evidence in support of the molecular chain theory, the membrane theory of Hess was dealt with critically; the author, in common with most other investigators, appears to prefer the former. Six methods for the determination of the molecular weight of cellulose and its derivatives were then described, and the difficulty of correlating and interpreting the resulting values was emphasized. Thus, chemical determinations of end-groups give the 'molecular weight' of the largest unit within which the atoms are bound by primary valencies; osmotic pressure and ultra-centrifuge methods measure only particle size and, therefore, depend on the degree of aggregation of the molecules; whilst viscosity measurements must be standardized against an absolute method.

The second part of the paper described how the methods devised by the British Cotton Industry Research Association for the preparation of modified cotton cellulose by the action of acids and oxidizing agents have enabled evidence in support of the chain theory to be obtained.

A second paper, entitled "Wood Pulp for the Rayon Industries", by L. Hebbs, contained some interesting side-lights on the influence of the early work of the late C. F. Cross. Thus, it was pointed out that so long ago as 1904 a pulp with an $\alpha$-cellulose content of 88.8 per cent had been produced by mercerization with alkali. Moreover, in 1906 an analytical method for the determination of $\alpha$-cellulose was outlined, which is essentially the same as that used to-day. The correlation of the copper number and the cuprammonium- and viscose-viscosities with the strength and cellulose purity of pulp was then discussed, the relationships being illustrated graphically. The elimination of resinous matter in the manufacture of wood pulp is greatly assisted by removal by washing and screening of the small sacs, medullary rays and short fibres in which it is concentrated, and by bleaching the pulp in several stages. Rapid replacement of cotton linters by wood pulp is expected.

In the third paper, Dr. R. Cuthill discussed the sorptive properties of the silk fibre, which are of considerable importance both from a theoretical and a practical point of view. Gases and vapours, nonelectrolytes in solution and pure liquids, suspended solids, electrolytes and dyes were dealt with in turn. 